\title{
EDITORIAL
}

\section{ISHRA una nueva revista científica para nuestra Universidad}

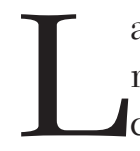

a Revista del Instituto Seminario de Historia Rural Andina que presentamos surge en un momento muy especial. El hasta entonces Seminario de Historia Rural Andina cuyos cincuenta años se cumplieron en el mes de marzo del presente año, ha pasado a denominarse Instituto Seminario de Historia Rural Andina, dejando de depender del Rectorado y pasando a conformar uno de los dos institutos de investigación de la Facultad de Ciencias Sociales. Este cambio es producto de la aplicación del Estatuto de la Universidad Nacional Mayor de San Marcos vigente a partir del 7 de junio del año en curso.

No se trata de un cambio menor, ni burocrático. Todo lo contrario. Es la expresión de la nueva política universitaria de promover la investigación bajo nuevos conceptos y estrategias. En el caso del Instituto Seminario de Historia Rural Andina, se trata de mantener las principales líneas de investigación ejecutadas en sus cinco décadas de existencia y adecuarlas a los nuevos cambios. En primer lugar, significa desarrollar un proceso de inserción a la Facultad de tal manera que los docentes y estudiantes principalmente de la Facultad de Ciencias Sociales, realicen actividades de investigación a través de grupos de investigación. En segundo lugar, que los resultados y productos que desarrollen se difundan a la comunidad a través de eventos académicos y publicaciones impresas y virtuales. En tercer lugar, que el Instituto Seminario de Historia Rural Andina construya un espacio de intercambio académico, social y cultural con la comunidad externa, considerando que su sede se ubica en el centro histórico de Lima y el edificio es patrimonio cultural.

Para alcanzar ello, desde fines de agosto que asumimos el encargo y hasta la actualidad, realizamos un diagnóstico y un plan con el apoyo de los actores involucrados. Así tuvimos talleres con docentes, estudiantes y egresados de Ciencias Sociales. Asimismo, conformamos un comité de gestión que establece los lineamientos centrales. Ello nos permitió identificar las principales demandas y expectativas expresadas luego en las siguientes estrategias:

Desarrollar actividades en la Facultad de Ciencias Sociales y en Colegio Real, sede del Instituto Seminario de Historia Rural Andina.

Difusión de dichas actividades a través de diversos medios disponibles.

La estrategia de desarrollar actividades en la Facultad de Ciencias Sociales nos permite interactuar de manera permanente con la comunidad interna. Especialmente que los estudiantes, docentes y egresados conozcan al Instituto Seminario de Historia Rural Andina, sus actividades, sus productos y su historia. Los talleres de diagnóstico mencionados, así como las conversaciones sostenidas con estudiantes, señalaron que era muy difícil para ellos ir hasta el Colegio Real, por lo que conocían muy poco del Instituto. Ello se había hecho más grave aún, cuando en marzo de 2015 hubo un incendio en dicha sede y se cortó la línea telefónica y la conexión a Internet. 
La segunda estrategia, busca solucionar de manera complementaria el problema indicado. Así, las actividades de difusión son centrales como estrategia transversal, ya que si bien el hoy Instituto Seminario de Historia Rural Andina, ha desplegado una gran producción académica sustentada en casi 500 publicaciones y 100 exposiciones, tal como sostiene Rosaura Andazabal en el primer artículo de esta revista, las generaciones actuales en nuestra Facultad no han podido conocerlas ni acceder a ellas. Por ello, es fundamental enfatizar en la difusión de las actividades y el conocimiento del Instituto, pues de esa manera se pueden involucrar en el diseño y desarrollo de proyectos de investigación e integrar grupos de investigación.

A partir de lo señalado hasta aquí, podemos señalar que las principales actividades del Instituto Seminario de Historia Rural Andina son:

Conversatorios del Instituto Seminario de Historia Rural Andina

Presentación de grupos de investigación

Publicaciones y presentación de publicaciones

Exposiciones y muestras

Talleres y cursos

El objetivo de los Conversatorios del Instituto Seminario de Historia Rural Andina, es promover el debate académico de temas desde una perspectiva multidisciplinaria. De esta manera, docentes, estudiantes y egresados se involucren en la construcción colectiva de un diálogo académico multidisciplinario. A partir de estos conversatorios se promueven nuevos temas y nuevos grupos de investigación.

En el caso de los grupos de investigación, se trata de conformar espacios en el cual docentes, estudiantes y egresados puedan proponer y desarrollar proyectos de investigación, elaborar sus tesis, artículos y ponencias, con miras a su difusión y publicación. A la fecha se han conformado dos grupos de investigación. El primero se denomina "Diseñando el Perú: intelectuales y política en el Perú” y el segundo "Gestión y educación patrimonial andina”. El primero investiga sobre los vínculos entre los intelectuales y su participación en la política a partir de un contexto histórico particular. El segundo tiene su núcleo en el proyecto arqueológico Pacopampa y su extensión hacia la promoción de investigaciones en torno a sitios arqueológicos y sitios históricos que son patrimoniales y que requieren una gestión integral, especialmente orientadas a la educación patrimonial.

Las publicaciones y presentación de publicaciones tienen por objetivo presentar a la comunidad académica los productos de los grupos de investigación, como contribución al conocimiento. De manera general, podemos señalar que adicional a los libros que se publiquen ya sean en edición propia o en coediciones, tenemos una serie de publicaciones denominada Cuadernos de investigación, donde se publican los resultados de las investigaciones de los grupos de investigación. Otra serie se denomina Fuentes para la Historia Andina, donde se difunden fuentes con un estudio preliminar. Asimismo, con este primer número iniciamos la Revista del Instituto Seminario de Historia Rural Andina. Se trata de ofrecer una revista de alto nivel académico con miras a su indización que difunda los avances y resultados de investigaciones, así como publicaciones recientes. La presentación de publicaciones ha sido pensada como eventos académicos de discusión y debate.

Las exposiciones son actividades de extensión universitaria, donde participan miembros de la comunidad interna y externa. Los talleres y cursos están pensados como actividades de responsabilidad social y tienen como objetivo contribuir en el fortalecimiento de vínculos con la comunidad interna y externa. En el caso de la comunidad interna, están orientados al fortalecimiento de capacidades de investigación, actualización y especialización de nuestros estudiantes, egresados y 
docentes. En el caso de la comunidad externa, están orientados a la creación de espacios de interacción académica y social con la sociedad compartiendo con ellos los resultados de las investigaciones y nuevo conocimiento generado luego de un adecuado proceso de transposición didáctica.

Deseo concluir esta presentación agradeciendo a las autoridades de la Facultad, a los estudiantes, docentes y egresados que están participando en nuestras actividades y los invitamos a continuar haciéndolo, así como dándonos sugerencias para mejorar nuestra gestión. Asimismo, deseo agradecer al Comité de Gestión del Instituto Seminario de Historia Rural Andina conformado por los profesores Mag. Luz Peralta y Mag. Freddy Cabanillas y los señores Lorenzo Huamaní y Jesús Llerena, representantes de los estudiantes. Otro agradecimiento al Mag. Alex Loayza, ex director del entonces Seminario de Historia Rural Andina quien consideró importante que el SHRA tuviera una revista. Fue él quien organizó el primer número como un Dossier, en el cual se reflexionara sobre el trabajo realizado durante sus cincuenta años a manera de balance. Con los cambios en la Dirección del Instituto Seminario de Historia Rural Andina y la aplicación de las directivas sobre investigación y publicaciones las designaciones pasaron a los docentes ordinarios. En este caso, la responsabilidad del primer número quedó en manos del Mag. Loayza. Finalmente agradecer al equipo de trabajo del Instituto, tanto a las y los investigadores, como al personal administrativo y del área de publicaciones, por su apertura y contribución permanente.

Dra. Carlota Casalino Sen

Directora (e)

Instituto Seminario de Historia Rural Andina

Facultad de Ciencias Sociales

Universidad Nacional Mayor de San Marcos 